\title{
Synthesis and Spectroscopic, Studies of Some New Piperidin-4-one Derivatives
}

Dalia Saad Mahdi Said ALkhafaji ${ }^{1}$, Abdel-Amir Mutlak Fenjan ${ }^{1}$, Abdul-Karim-Talaq Mohammad ${ }^{2}$

${ }^{1}$ Department of Chemistry, College of Science for women, University of Baghdad, Baghdad-Iraq.

${ }^{2}$ Department of Chemistry, College of Science, University of Anbar, Ramadi-Iraq.

Corresponding Author: drmohamadtalaq@gmail.com.

\section{Abstract}

The homologous series of 2,6-bis(4-Subtituetphenyl)-3-methylpiperidin-4-one compounds were synthesized using Mannich condensation. Then Five series have been synthesized by reaction of different reagents of semicarbazide. With 2,6-bis(4-Subtituetphenyl)-3-methylpiperidin-4-one to sythesize target compounds $2 \mathrm{a}-2 \mathrm{f}, 2 \mathrm{a}-2 \mathrm{f}, 3 \mathrm{a}-3 \mathrm{f}, 4 \mathrm{a}-4 \mathrm{f}, 5 \mathrm{a}-5 \mathrm{f}$ and $6 \mathrm{a}-6 \mathrm{f}$. The chemical structures of the molecules were characterised by FT-IR, 1D NMR and CHN elements analysis.

[DOI: $10.22401 /$ JNUS.21.2.10]

Keyword: Piperidin-4-one, Spectroscopic, studies, FT-IR, ${ }^{1} \mathrm{H}$ NMR, ${ }^{13} \mathrm{C}$ NMR.

\section{Introduction}

Piperidones are named by the location of the nitrogen or amine group and the carbonyl group on the ring. It was used in pharmaceutical companies and chemical manufacturers as starting material having antimicrobial activity [1]. Compounds having piperidone are associated with diverse pharmacological properties such as anticancer, anti-microbial, anti-convulsant, antiviral, anti-HIV, anti-fungal and antimycobacterial. [2].

The piperidine ring is an ubiquitous structural feature of many alkaloid natural products and drug candidates. Watson et al. asserted that during a recent 10-year period there were thousands of piperidine compounds mentioned in clinical and preclinical studies. $[3,4]$.

Baliah and his coworker developed an elegant method of synthesis of 2,6diarylpiperidin-4-onebsased on the earlier work of Petrenko-Kritschenko et al. [5-16] The earlier reaction involves the condensation of an ester of acetonedicarboxylic acid with an aromatic al- dehyde and ammonia or a primary amine, leading to the formation of 2,6-diaryl4-oxopiperidine-3,5-di- carboxylates or their $\mathrm{N}$-substituted derivatives [17-20].

The hetero Diels- Alder (HDA) reaction of imines with Danishefsky' sdiene (1-methoxy3-trimethylsiloxy-1, 3-butadiene) is an efficient method for construction of functionlized 2,3-dihydro-4-pyridones with control of region-, diastereo- and enantioselectivity [21-23].

Unlike piperidines, straightforward synthetic routes to substituted piperidin-2,4diones are limited.[24] Retrosynthesis of piperidin-2,4-diones usually involves 3,4disconnection or 1,2-disconnection. The synthetic strategies are usually based on $\delta$ amino $\beta$-ketoester. Synthetic strategy of synthesize 3,5-bis (benzylidene) piperidin-4one cyclisation involved by Dieckmann cyclisation, [25-28] or base cyclisation.[30] For piperidin-2-ones a [4+2] cycloaddition is also feasible.

\section{Experimental}

\section{1 Materials}

4-Chlorobenzaldehyd, Butanone, Ammonium acetate, Ethanol, 4nitrobenzaldyhyde, Thionyichloride, Ethylchloroacetate, Tetrahydrofurane, Thiosemecarbazide, Hydrogen chloride, Aceticaci, Aceticanhydride, Benzen, Semicarbazide hydrochloride, Sodium acetate, Acetonitril, Hydroxylamine hydrochloride, Pyridine, Triphenyl phosphine, Iodine, Potassium carbonate, Triethylamine, Chloroform, Calcium chloride, Pipyridine, Ammonium chloride, Potassium cyanide, Sodium hydrogen carbonate, 4-Chloroaniline, Urea, Hydrazine hydrate, Sodium borohydride, 4-Amino benzoicacid, 4-hydroxybenzaldehyde, .2,4dichloro benzaldehyde.

The chemicals were used directly as received without further purification. Thinlayer chromatography (TLC) was performed on pre-coated silica-gelon aluminum plates using 4:6 ratio of ethyl acetate and petroleum ether as an eluent. 


\section{2 Synthesis}

Synthetic of intermediates 1a-1fand title compounds 2a-f, 3a-f, 4a-f, 5a-f and 6a-f are present in Scheme 1. Compound 1a-f was prepared as the method reported in literature [30], Mannich condensation reaction were applied to synthesized Piperidin-4-one in the respective ratio of $(2: 1: 1)$ using $p$ chlorobenzaldehyde and butanon with ammonium acetate, respectively in the medium of $95 \%$ ethanol heated on a hot plate up to the boiling range and kept overnight. The product piperidine-4-one was separated after 3 days and it was recystallized by slow evaporation.

2. 3. 1 Synthesis of compounds target compounds 2-(2,6-bis(4-substutedphenyl)-3methylpiperidin-4-

ylidene)hydrazinecarbothioamide $2 \mathrm{a}-\mathrm{f}$

The title compounds were synthesized according to a method described by Sampathet;al [31].All compounds have been prepared in the same methods we will present the synthesis of compound 2a as example:

Mannich condensation reaction were applied to synthesized Piperidin-4-one in the respective ratio of $(2: 1: 1)$ using $\boldsymbol{p}$ Chlorobenzaldehyde and butanon with ammonium acetate, respectively in the medium of $95 \%$ ethanol heated on a hot plate up to the boiling range and kept overnight [32]. The product piperidine-4-one was separated after 3 days and it was recystallized by slow evaporation.

The analytical, FT-IR, ${ }^{1} \mathrm{H}$ NMR and ${ }^{13} \mathrm{C}$ NMR for compounds $\mathbf{1 a}$ are summarized as follows (for example):

\section{2,6-bis(4-chlorophenyl)-3-methylpiperidin-}

4-one 1a Yield $65 \%$. M.p. $(218-220)^{\circ} \mathrm{C}$. Anal: Calc $(\%) \mathrm{C}_{18} \mathrm{H}_{17} \mathrm{Cl}_{2} \mathrm{NO}$ M.W :334.24 C, 64.68; $\mathrm{H}, 5.13$; N, 4.19;Cl,21.21;O,4.79; Found, C, 64.02; H, 5.93; N, 4.83. IR v max $(\mathrm{KBr})\left(\mathrm{cm}^{-1}\right)$ : $3475.73(\mathrm{NH}), 2974.23\left(\mathrm{CH}_{3}\right), 3035.96(\mathrm{Ph}-$ $\mathrm{CH}), \quad 1708.93 \quad(\mathrm{C}=\mathrm{O}), \quad 1581.63 \quad(\mathrm{C}=\mathrm{C}$ aromatic), $682.80(\mathrm{C}-\mathrm{Cl}) .{ }^{1} \mathrm{H}$ NMR $\delta(\mathrm{ppm})$ (Aceton): 7.21 (d 2H), 7.04 (d 2H), 7.83 (d 2H), 8.05 (d 2H), 2.42 (S NH), $2.72(\mathrm{~d} 2 \mathrm{H})$, $2.45(\mathrm{~S} \mathrm{1H}) .2 .37(\mathrm{~d} \mathrm{1H}), 2.27(\mathrm{~d} \mathrm{1H}), 1.02(\mathrm{~S}$ $\mathrm{CH} 3) .{ }^{13} \mathrm{C}$ NMR $\delta$ (ppm) (Aceton): 168.34 $(\mathrm{C}=\mathrm{O}), \quad 115.10-149.03$ (aromatic), 46.23 $\left(\mathrm{CH}_{2}\right), 50.13(\mathrm{CH}), 63.20(\mathrm{CH}), 68.34,15.16$ (CH3).
2. 3. 2 Synthesis of compounds target compoundsSynthesis of compounds (Z)-2(2,6-bis(4-Subsphenyl)-3-methylpiperidin-4ylidene)hydrazinecarboxamide $2 \mathrm{a}-\mathrm{f}$

A mixtur of 3-methyl-2,6-bis(4-Rphenyl)piperidin-4-one $(0.5 \mathrm{~g}, 0.0015 \mathrm{mml})$ with thiosemecarbazide $(0.1365 \mathrm{gt}, 0.0015 \mathrm{mmol})$ in ( $15 \mathrm{ml}$ ethanol with (3) drops of hydrogen chloride was refluxed for $2 \mathrm{hrs}$. After the reaction was completed, the solid product obtained was filtered off, dried and recrystallized from ethanol.

The analytical data for compound $\mathbf{2} \mathbf{b}$ are presented (for example) as fellow:

\section{(Z)-2-(2,6-bis(4-bromophenyl)-3- methylpipridin-4-hydrazinecarbothiomide 2b}

Yield $70 \% \quad \mathrm{Mp}(172-174) \quad{ }^{\circ} \mathrm{C} \quad \mathrm{M} . \mathrm{W}: 370.15$ Anal Calc (\%) $\mathrm{C}_{19} \mathrm{H}_{20} \mathrm{Br}_{2} \mathrm{~N}_{4} \mathrm{~S}$ C,45.98; H,4.06; $\mathrm{Br}$, 32.20; N,11.29; S,6.46, Found, C,45.12; $\mathrm{H}, 4.87 ; \mathrm{N}, 11.94$. IR $v \max (\mathrm{KBr})\left(\mathrm{cm}^{-1}\right)$ : 3165.42-3043.87 $\left(\mathrm{NH}_{2}\right), \quad 3214.97 \quad(\mathrm{NH})$, $2825.76\left(\mathrm{CH}_{3}\right), 3024.74(\mathrm{Ph}-\mathrm{CH}), 1042.53$ $(\mathrm{C}=\mathrm{S}), \quad 1421.86,1415,63 \quad(\mathrm{C}=\mathrm{C}$ aromatic $)$, $642.39(\mathrm{C}-\mathrm{Br}), 2435.82(\mathrm{~S}-\mathrm{H}), 1589.76(\mathrm{C}=\mathrm{N})$. ${ }^{1} \mathrm{H}$ NMR $\delta$ (ppm) (Aceton): $9.08\left(\mathrm{~S} \mathrm{NH}_{2}\right), 8.12$ (d 2H), 8.03(d 2H), 7.67 (d 2H), 7.02 (d 2H), $6.14(\mathrm{~S} \mathrm{NH}), 3.24(\mathrm{~S} \mathrm{NH}), 3.76(2 \mathrm{H})$, 2.49 (t 1H), 2.56-2.19 (dd CH), $0.73\left(\mathrm{t} \mathrm{CH}_{3}\right)$. 13 NMR $\delta$ (ppm) (Aceton): 163.29 $(\mathrm{C}=\mathrm{S}), 161.32(\mathrm{C}=\mathrm{N}), \quad 135.17-\quad 162.07$ (aromatic), $70.67(\mathrm{C}=\mathrm{N}), 66.94(\mathrm{C}-\mathrm{N}), 42.27$ $\left(\mathrm{CH}_{2}\right), 18.37\left(\mathrm{CH}_{3}\right)$.

2.3.3. Synthesis of compounds 1-acyl-2,6bis(4-substphenyl)-3-methyl pipridine-4-one 2a-f

The title compounds have been prepared according to method described in previous section for synthesis of 3a-f.

The analytical data for compound $\mathbf{3} \mathbf{c}$ are presented (for example) as fellow:

\section{(E)-2-(2,6-bis(4-hydroxyphenyl)-3- methylpiperidin-4-}

ylidene)hydrazinecarboxamide $3 c \quad$ Yield 78\%. $\quad$ M.p.(187-189) ${ }^{\circ} \mathrm{C} . \quad \mathrm{C}_{19} \mathrm{H}_{22} \mathrm{~N}_{4} \mathrm{O}_{3}$. M.W:354.40 Anal: Calc. (\%) C,64.39;H,6.26; N,15.81;O,13.54; Found, C, 65.12; H, 5.87; N, 4.90; IR $v$ max $(\mathrm{KBr})\left(\mathrm{cm}^{-1}\right): 3497.64,3387.92$ $\left(\mathrm{NH}_{2}\right), 3593.37(\mathrm{NH}), 2986.28\left(\mathrm{CH}_{3}\right), 3055.37$ $(\mathrm{Ph}-\mathrm{CH}), \quad 1697.82(\mathrm{C}=\mathrm{O}), \quad 1593.64,1587.32$ 
$(\mathrm{C}=\mathrm{C} \quad$ aromatic), $3264.52 \quad$ (C$\mathrm{OH}) .1598 .40(\mathrm{C}=\mathrm{N}),{ }^{1} \mathrm{H} \quad \mathrm{NMR} \quad \delta \quad(\mathrm{ppm})$ (Aceton): $9.57\left(\mathrm{~S} \mathrm{NH}_{2}\right), 8.79$ (d $\left.2 \mathrm{H}\right), 8.58$ (d 2H), 7.95 (d 2H), 7.62 (d 2H) $5.84(\mathrm{~S} \mathrm{NH})$, $5.02(\mathrm{~S} N \mathrm{NH}), 4.81(2 \mathrm{H}), \quad 3.14(\mathrm{t} 1 \mathrm{H})$, 2.96(d1H), 2.57(d1H), $1.32(\mathrm{t} \mathrm{CH} 3) .{ }^{13} \mathrm{NMR} \delta$ (ppm) (Aceton): $171.187 \quad(\mathrm{C}=\mathrm{O}), \quad 130.33$ 165.14 (aromatic), $163.12(\mathrm{C}=\mathrm{N}) 63.34(2 \mathrm{C}$ $\mathrm{N}), \quad 79.72(\mathrm{C}-\mathrm{N}), \quad 69.87(\mathrm{C}-\mathrm{N}), \quad 64.39\left(\mathrm{CH}_{2}\right)$, 18.24( $\left(\mathrm{CH}_{3}\right)$.

2.3.4. Synthesis of compounds (E)-2,6bis(4-Substphenyl)-3-methyl-4-oneoxime 4a-f A mixture of compound [1a] $(0.501 \mathrm{~g})$ and $(5 \mathrm{ml})$ acetic anhydride in $(5 \mathrm{ml})$ acetic acide was refluxed for $(5 \mathrm{hrs})$.then filtered dried and recrystallized from ethanol and washed with distilled water.

The analytical data for compound $4 \mathrm{~d}$ are presented as fallow (for example):

\section{1-acyl-2-bis(4-methoxyphenyl)-3-}

methylpipridine-4-one 4d Yield $74 \%$. M.p.(176-178) ${ }^{\circ} \mathrm{C} . \quad \mathrm{C}_{21} \mathrm{H}_{26} \mathrm{~N}_{4} \mathrm{O}_{3}$. M.W:382.46 Anal: Calc. (\%) C,65.95; H, 6.85; N, 14.65; O, 12.55; Found, C, 65.08; H, 5.85; N, 4.93; IR $v$ max_(KBr) $\quad\left(\mathrm{cm}^{-1}\right): \quad 3326.54,3187.52$ $\left(\mathrm{NH}_{2}\right), 3514.76(\mathrm{NH}), 2948.83\left(\mathrm{CH}_{3}\right), 3024.93$ $(\mathrm{Ph}-\mathrm{CH}), \quad 1664.89 \quad(\mathrm{C}=\mathrm{O}), \quad 1574.63,1485.82$ $(\mathrm{C}=\mathrm{C} \quad$ aromatic), $1025.36 \quad$ (CCl).1589.24(C=N), ${ }^{1} \mathrm{H} \quad \mathrm{NMR} \quad \delta \quad(\mathrm{ppm})$ (Aceton): $8.87\left(\mathrm{~S} \mathrm{NH}_{2}\right), 7.54(\mathrm{~d} 2 \mathrm{H}), 7.21$ (d 2H), 6.88 (d 2H), $6.53(\mathrm{~d} \mathrm{2H}) 5.22(\mathrm{~S} \mathrm{NH})$, $4.27(\mathrm{~S} N \mathrm{NH}), 4.04(2 \mathrm{H}), 2.41(\mathrm{t} 1 \mathrm{H})$, 2.32(d1H), 2.16(d1H) 0.83 ( t CH3). ${ }^{13} \mathrm{NMR} \delta$ (ppm) (Aceton): $162.19 \quad(\mathrm{C}=\mathrm{O}), \quad 113.83$ 161.24 (aromatic), $160.86(\mathrm{C}=\mathrm{N}) 60.24(2 \mathrm{C}-$ N) 67.81(C-N), 64.23(C-N), $62.86\left(\mathrm{CH}_{2}\right)$, $13.25\left(\mathrm{CH}_{3}\right)$

2.3.5. Synthesis of compounds 4-amino-2,6bis(4-subustphenyl)-3-methylpipridine-4carbonitrile 5a-f

Amixture of compound [1a] (1.5 mmol, $0.5 \mathrm{~g})$ and $(0.5 \mathrm{~g}, \quad 7.3 \mathrm{mmol})$ hydroxylamine hydrochloride dissolved in $(5 \mathrm{ml})$ ethanol and $(0.5 \mathrm{ml})$ pyridine and refluxed for $(1.30 \mathrm{hrs})$ added $(20 \mathrm{~g})$ crushed ice, stirrer, filtered, dried and recystallized from ethanol.

The analytical data for compound $5 \mathrm{e}$ are presented as fallow (for example):
(E)-3-methyl-2,6-bis(4-

nitrophenyl)piperidin-4-one oxime 5e Yild 97\% $\mathrm{Mp}(193-195)^{\circ} \mathrm{C}$ M.W:370.36 Anal Calc (\%) $\mathrm{C}_{18} \mathrm{H}_{18} \mathrm{~N}_{4} \mathrm{O}_{5}$ C,58.37; H, 4.90; N, 15.13; O,21.60, Found, C, 58.90; H, 4.06; N, 15.87; IR 0 max_ $(\mathrm{KBr})\left(\mathrm{cm}^{-1}\right): 3429.14(\mathrm{OH}) 3397.27$ $(\mathrm{NH}), \quad 2974.23 \quad\left(\mathrm{CH}_{3}\right), 3085.96 \quad(\mathrm{Ph}-\mathrm{CH})$, $1696.72 \quad(\mathrm{C}=\mathrm{N}), \quad 1598.65,1582.31 \quad(\mathrm{C}=\mathrm{C}$ aromatic), 1091.71 (C-NO). ${ }^{1} \mathrm{H}$ NMR $\delta(\mathrm{ppm})$ (Aceton): $9.89(\mathrm{OH}), 8.63(\mathrm{~d} 2 \mathrm{H}), 7.96(\mathrm{~d} 2 \mathrm{H})$, 7.72 (d 2H), 7.58 (d 2H), 4.39 (d 2H), 3.26 (t 1H) 6.4. (S NH), $2.94(2 \mathrm{H}), 2.62(\mathrm{~d} 2 \mathrm{H}), 0.98$ (t 2 CH3). ${ }^{13}$ NMR $\delta \_(p p m)$ (Acetone): 129.63163.15 (aromatic), $69.68(\mathrm{C}=\mathrm{N}), 64.08,32.26$ $\left(\mathrm{CH}_{2}\right), 34.03(\mathrm{CH}), 17.84\left(\mathrm{CH}_{3}\right)$.

2.3.6. Synthesis of compounds 4-amino-2,6bis(4-subustphenyl)-3-methylpipridine-4carbonitrile 6a-f

A mixture of compound [1a] $(0.86 \mathrm{~g})$ and ammonium chloride $(0.207 \mathrm{~g})$ and potassium cyanide $(0.205 \mathrm{~g})$ then added $(10 \mathrm{ml})$ of ammonia stirring for $(20 \mathrm{hrs})$ at room temperature, then filtered, dried and recystallized from ethanol.

The analytical data for compound $6 f$ are presented (for example) as fellow:

\section{4-amino-2,6-bis(2,4-dihydroxyphenyl)-3- methylpiperidine-4-carbonitrile of Yild $81 \%$} Mp (215-217) ${ }^{\circ}$ C, M.W:355.39 Anal Calc (\%) $\mathrm{C}_{19} \mathrm{H}_{21} \mathrm{~N}_{3} \mathrm{O}_{4} \mathrm{C}$, 64.21; H, 5.96; N, 11.82; O, 18.01. Found, C, 64.86; H, 5.11; N, 11.08; IR $v \max (\mathrm{KBr})\left(\mathrm{cm}^{-1}\right): 3198.92,3172.78(\mathrm{NH} 2)$, $3398.87(\mathrm{NH}), 2897.85\left(\mathrm{CH}_{3}\right), 3039.76(\mathrm{Ph}-$ $\mathrm{CH}), 3093.82(\mathrm{C} \equiv \mathrm{N}) 1679.79(\mathrm{C}=\mathrm{N}), 1593.39$ $(\mathrm{C}=\mathrm{C} \quad$ aromatic $), \quad 771.53 \quad(\mathrm{C}-\mathrm{OH})$, 3124.68(C=NH). ${ }^{1} \mathrm{H}$ NMR $\delta$ (ppm) (Aceton): (d 2H), 8.73 (d 2H), 7.96 (d 2H), 7.73 (d 2H), 7.68 (S NH2), 3.08 (d 2H), $2.98(\mathrm{NH}), 2.85$ (1 H), 2.95 (d 1H), 2.87(S NH), 0.97 (dCH3). 13 NMR $\delta$ (ppm) (Aceton): 116.15- 147.23 (aromatic), 68.82(CH2), 56.45-53-50 (C-N), $50.76(\mathrm{CH}), 43.25(\mathrm{C}), 15.26(\mathrm{CH} 3)$.

\section{2 Measurements}

${ }^{1} \mathrm{H}$ and ${ }^{13} \mathrm{C}$ NMR spectra were recorded in dimethylsulphoxide (Aceton- $\mathrm{d}_{6}$ ) and (Ethanol$\left.\mathrm{d}_{6}\right)$ at $298 \mathrm{~K}$ on a Bruker500 \&400 $\mathrm{MHz}$ Ultrashied $^{\text {TM }}$ FT-NMR spectrometer equipped with a $5 \mathrm{~mm}$ BBI inverse gradient probe. Chemicals shift was referenced to internal 
tetramethylsilane (TMS). The concentration of solute molecules was $50 \mathrm{mg}$ in $1.0 \mathrm{ml}$ DMSO. Standard Bruker pulse programs [32] were used throughout the entire experiment, at School of Chemical Sciences, Bangalor India. Fourier-Transform Infra-Red (FT-IR) spectra were obtained using $\mathrm{KBr}$ pellets and the spectra were recorded in the range of 4000$400 \mathrm{~cm}^{-1}$ using a 8400s fourier transitions infrared spectrometer Shimadzu, Japan At the University of Baghdad, College of Science for Women, Chemistry Department.

Elemental (CHN) microanalyses were performed using a Perkin Elmer 2400 LS Series CHNS/O analyzer.

\section{Results and Discussion}

\section{1 Synthesis and characterization}

The symmetric of Piprodin-4-one derivatives were synthesized according to the modified procedures were reported in the literature and synthetic methodology are shown in Scheme.(1). Piprodin-4onecompounds core compound 1a-1f, were prepared based on Mannich condensation reaction between various substituted benzaldehyde and butanon with ammonium acetate, ratio of $(2: 1: 1)$ respectively in ethanolic solution (Scheme 3.1). The pure compounds were obtained by recrystallization from absolute ethanol.

Refluxing a mixture of 3-methyl-2,6-bis(4R-phenyl)piperidine-4-one with thiosemicarbazide in precent of hydrogen hydrochloride in ethanol as solvent give target compounds $2 \mathrm{a}-2 \mathrm{f}, \mathrm{Scheme}(1)$. In the same way compounds $3 \mathrm{a}-3 \mathrm{f}$ have been prepared by condensation reaction of by dissolved semicarbazidehydrochloride and sodium acetate anhydrous in distilled water, and 3methyl-2,6-bis(4-R-phenyl) piperidine-4-one in ethanol as solvent.

Treatments of 3-methyl-2,6-bis(4-Rphenyl) piperidine-4-one and acetic anhydride in present of acetic acid gave titled compounds 1-acyl-2,6-bis(4-substphenyl)-3-methyl

pipridine-4-one $4 \mathrm{a}-4 \mathrm{f}$, after $\mathrm{h}$ hours refluxing. Compounds $5 \mathrm{a}-5 \mathrm{f}$ were prepared based on condensation reaction between 3-methyl-2,6bis(4-R-phenyl) piperidine-4-one and hydroxylamine hydrochloride dissolved in ethanol and pyridine, recrystallized from ethanol. In the same way, compounds 6a-6f also synthesized by condensation reaction of between 3-methyl-2,6-bis(4-R-phenyl) piperidine-4-one and ammonium chloride and potassium cyanide then added ammonia stirring for (20 hrs) at room temperature.

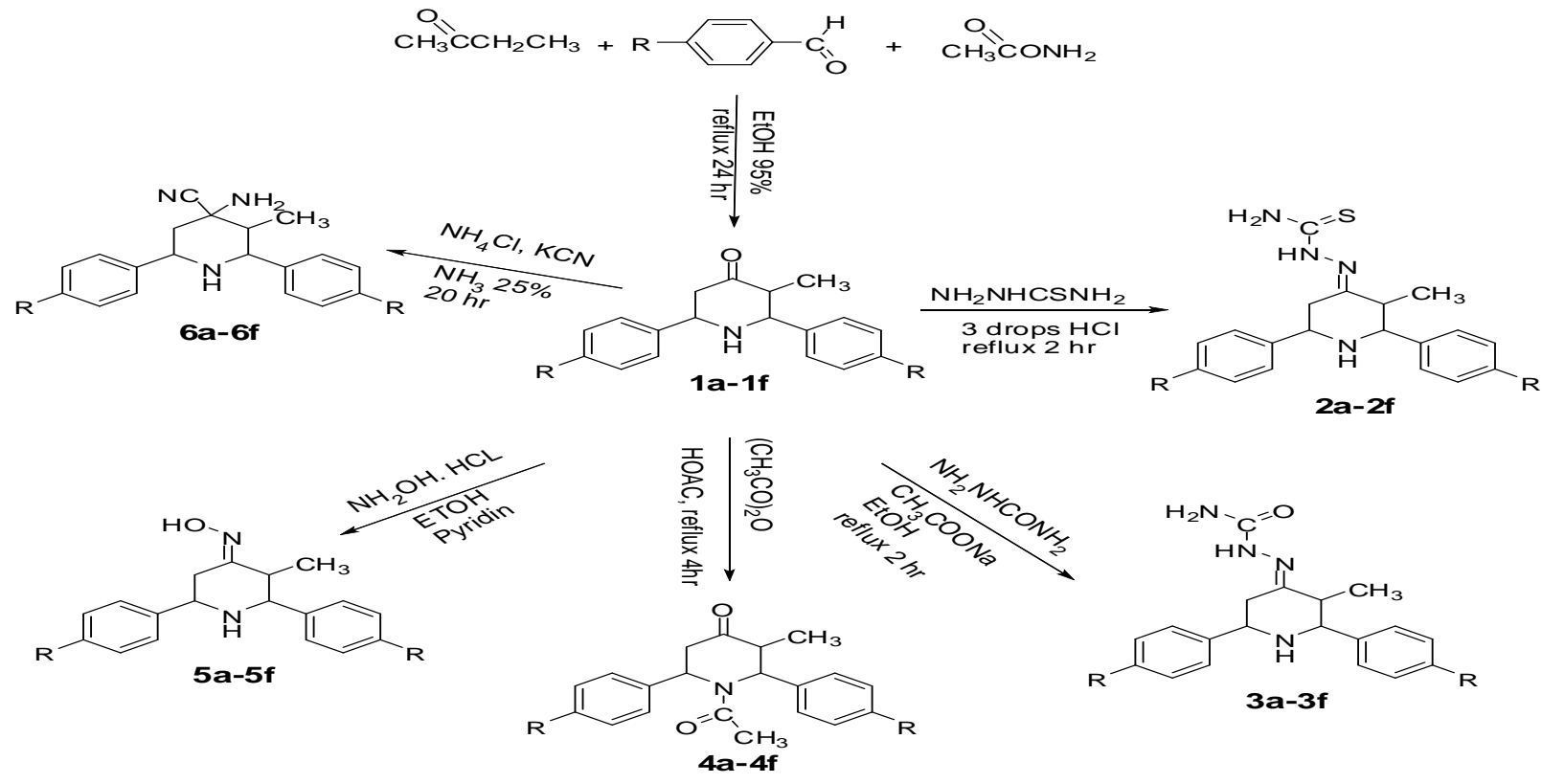

$\mathrm{R}=4-\mathrm{Cl}, 4-\mathrm{NO}_{2}, 4-\mathrm{Br}, 4-\mathrm{OH}, 4-\mathrm{OCH}_{3}, 2,4 \mathrm{dihydroxy}$

Scheme (1): The synthetic route toward synthesis target compounds 1, 2, 3, 4, 5 and 6. 


\section{2 FT-IR Study}

The FT-IR instrument gives characteristics of various functional groups of the target compounds. All the spectra of the titled compounds 1a-1f, 2a-2f, 3a-3f, 4a-4f, 5a-5f, and 6a-6f showed similarities except the different in functional group.

The weak absorption band that appeared at the range of $2987.98-2841.29 \mathrm{~cm}^{-1}$ assigned to the $\left(\mathrm{vC}_{\mathrm{ph}}-\mathrm{C}-\mathrm{H}\right)$ benzylic [35]. Absorption bands can be assigned by symmetric and asymmetric stretching $\left(\mathrm{vCH}_{3} \mathrm{~s}, \quad \mathrm{vCH}_{3} \mathrm{as}\right)$ which appeared within the range of 2931$2955 \mathrm{~cm}^{-1}$ while weak absorption bands for $\left(v \mathrm{CH}_{2} \mathrm{as}, v \mathrm{CH}_{2} \mathrm{~s}\right)$ appeared at the range of 2851-2874 $\mathrm{cm}^{-1}$. In addition to these bands, there is another band observed at the range of $1445-1489 \mathrm{~cm}^{-1}$ which can be ascribed to stretching of $v \mathrm{C}-\mathrm{H}$ [36]. The existence of the aromatic ring in all series compounds is suggested by the following bands: a weak absorption band at 3019-3075 $\mathrm{cm}^{-1}$ for aromatic $\left(\mathrm{C}_{\mathrm{ph}}-\mathrm{H}\right)$ stretching vibration [33]. On the other hand, a strong band at the frequency range of $1597.94,1584.37 \mathrm{~cm}^{-1}$ assigned for the phenyl ring stretching $(\mathrm{vC}=\mathrm{C})$ [35].

Carbonyl group $\mathrm{C}=\mathrm{O}$ in series compounds 1a-1f, 3a-3f, and 4a-4f, can be characterized by the strong band which be observed at the range of $1708.93 \mathrm{~cm}^{-1}$. On the other hand, the $\mathrm{C}=\mathrm{N}$ gave a band at the frequency $1681.93 \mathrm{~cm}^{-1}$ with medium intensity in respective series 2a-2f, 3a-3f and 5a-5f.

Likewise, in the fingerprint region the band at $1256 \mathrm{~cm}^{-1}$ is due to the ether $\mathrm{C}-\mathrm{O}$ stretching.

In series compounds $2 \mathrm{a}-2 \mathrm{f}, 3 \mathrm{a}-3 \mathrm{f}$, and $6 \mathrm{a}-$ $6 f$ the broad band, which appeared at the frequency $\mathrm{cm}^{-1}$ assign to $\mathrm{NH}_{2}$ group at the frequency range $3263.56-3174.83 \mathrm{~cm}^{-1}$. In the same way the broad band at the frequency $3414.00-3456 \mathrm{~cm}^{-1}$ assign to $\mathrm{OH}$ group in series compounds $5 \mathrm{a}-5 \mathrm{f}$.

\section{3. $2{ }^{1} \mathrm{H}$-NMR and ${ }^{13} \mathrm{C}$-NMR Study}

${ }^{1} \mathrm{H}-\mathrm{NMR}$ data assignment for 1a-1f, 2a-2f, 3a-3f, 4a-4f, 5a-5f, and 6a-6f. ${ }^{1} \mathrm{H}-\mathrm{NMR}$ spectra in all series compounds showed the two doublet in the most of down field at the chemical shift 8.09 (d 2H), 7.88 (d 2H), 7.56 (d 2H), 7.39 (d 2H), ppm which can be assign to aromatic protons. In the same way in titled compounds in series 2a-2f, 3a-3f, and 6a-6f showed at downfield region the signal corresponding to the proton amine $\left(\mathrm{NH}_{2}\right)$ group, which integrates $2 \mathrm{H}$ at $\delta=8.24 \mathrm{ppm}$.

While the protonts of $\mathrm{NH}$ group as singlet at the resonance $\delta=6.4$. ppm and $\delta=8.24 \mathrm{ppm}$ and two doublet at $\delta=8.24 \mathrm{ppm}$ and $\delta=8.24 \mathrm{ppm}$ in respective series $1 \mathrm{a}-1 \mathrm{f}, 2 \mathrm{a}-2 \mathrm{f}$, $3 a-3 f$, 5a-5f, and 6a-6f. On the other hand the other broad band appeared at the chemical shift range 8.94-9.92 ppm which integrated at one hydrogen corresponding to $\mathrm{OH}$ group in respective compounds $5 \mathrm{a}-5 \mathrm{f}$.

All title compounds showed a doublet at the high field corresponding to $\left(\mathrm{CH}_{3}\right)$ group which appeared at the chemical shift $0.86 \mathrm{ppm}$. The proton of heterocyclic ring in all titled compound appeared at $4.06(\mathrm{~d} 2 \mathrm{H})$, $2.92(\mathrm{t} 1 \mathrm{H}), 2.73$ (d 2H), 2.39 (d 2H). 

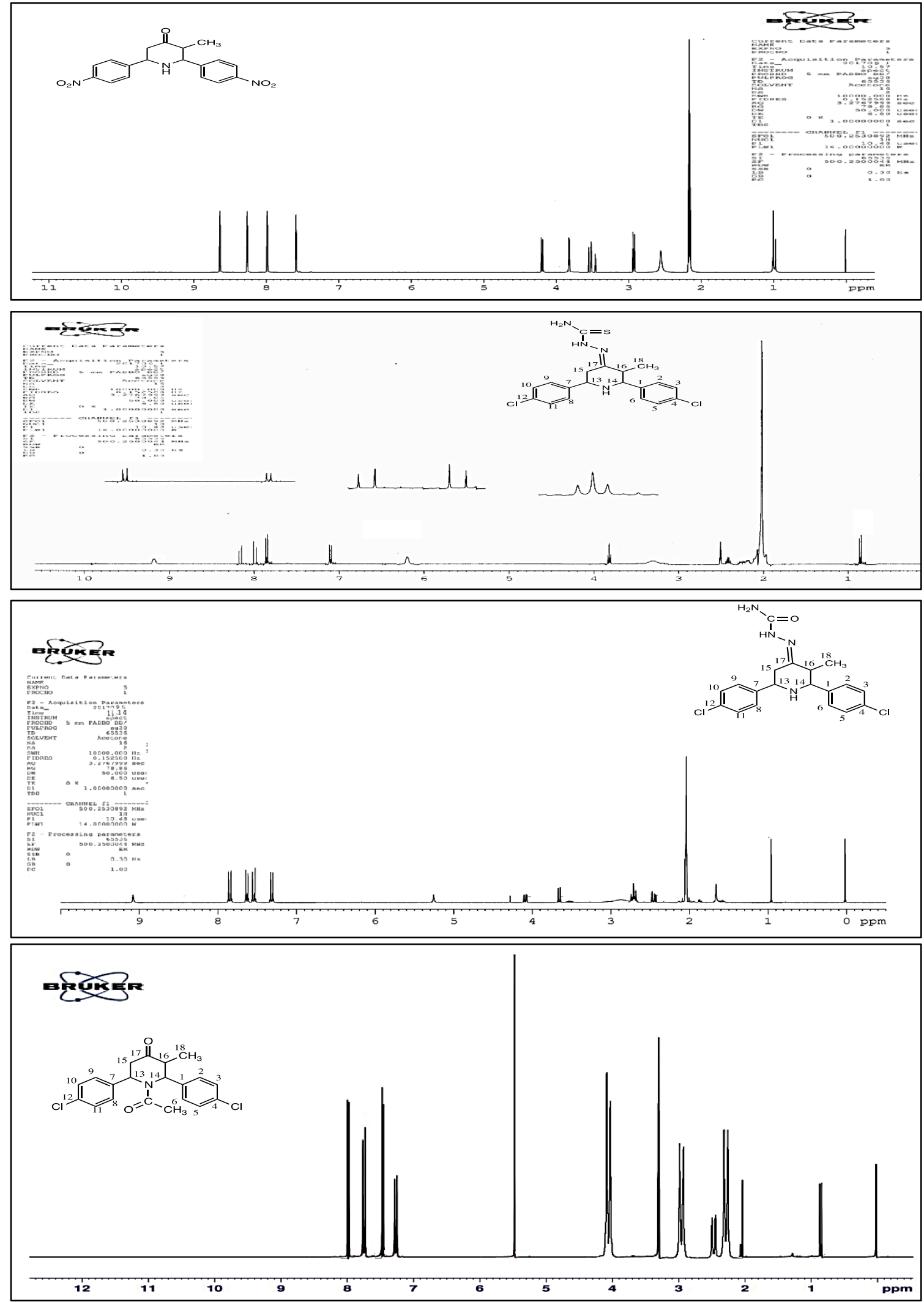

Fig.(1): Showed some ${ }^{1}$ H NMR spectra of selective compounds.

Analysis of the HMQC for the protonated carbons of the additive rules. The resonances due to the carbonyl group of titled compounds 1a-1f and 4a-4f are located in the downfield region $\delta=166.04-166.29$, ppm $\delta=171.11$ -
174.52 respectively. Moreover, the signal within the range of $\delta=67.04-68.87 \mathrm{ppm}$ can be attributed to the $\mathrm{C}$ in the imine $(\mathrm{CH}=\mathrm{N})$ group. The resonance appear the frequency ranges $\delta=134.11-138.66 \mathrm{ppm}$, 
122.3-123.01 ppm, 132.3-135.56 ppm, 131.0$132,59 \mathrm{ppm}$, due to the aromatic carbons in aromatic ring. Moreover, the spectra of title compounds confirmed that the signal at the resonance $64.28,32.4935 .21$ assign for carbons of heterocyclic ring. While the methyl group appear at the chemical shift $16.27 \mathrm{ppm}$.
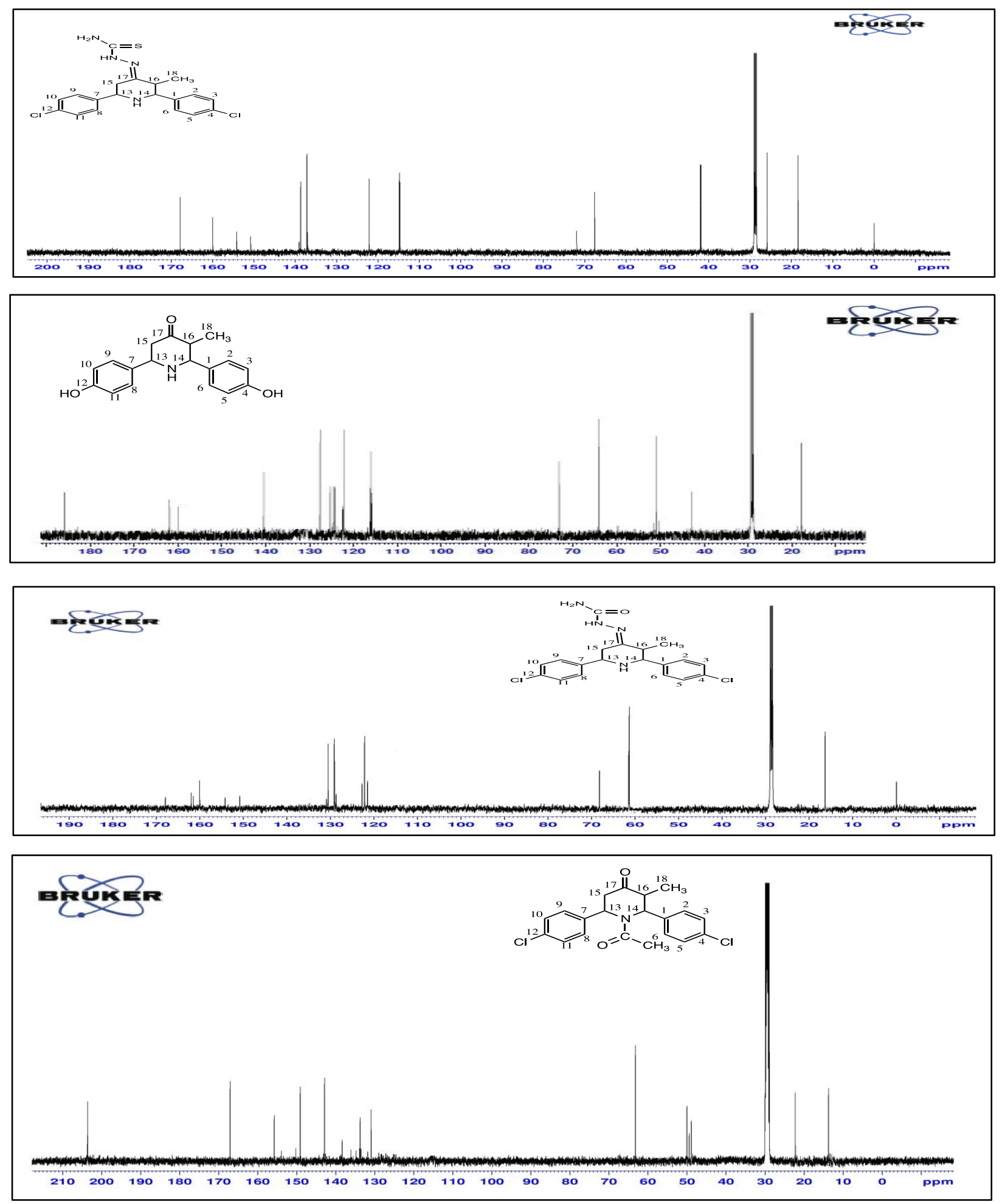

Fig.(2): Show the spectra of selective compounds. 


\subsection{Conclusion}

In this paper the synthesized and characterization of Piperidin-4-one, derivatives as core compound to use in other reaction with different nucleophles such as hydrazinecarbothioamide, hydrazinecarboxamide, acetic anhydride, hydroxylamine hydrochloride and ammonium chloride. These compound have been characterized by $\mathrm{CHN}$ analysis, FT-IR and 1D NMR ( ${ }^{1} \mathrm{H}$ NMR and ${ }^{13} \mathrm{C}$ NMR).

\section{Acknowledgement}

The authors would like to thank university of Baghdad college of science for women for providing the FT-IR and for samples NMR studies at Indian Institute of Science, Bengaluru is gratefully acknowledged.

\section{References}

[1] Soundarrajan C., Saraswathi K., Asiyaparvi A. "Piperidone synthesis using amino acid: A promising scope for green chemistry", Microchemical Journal, 98, 204-206, 2011.

[2] Sharma P. K., Fogla, A., Rathore, B. S., Kumar, M. "Synthesis and antimicrobial activity of structurally flexible heterocycles with the 1,4-thiazine heterosystem", Research on Chemical Intermediates, 37, 1103-1111. 2011.

[3] Watson P. S., Jiang B., Scott B. A, "Diastereoselective Synthesis of 2,4Disubstituted Piperidines: Scaffolds for Druge Discovery”, Org. Lett, 2, 3679-3681. 2000.

[4] Patrick D., Paula B., Millwood A. Peter, D. S. "Asymmetric routes to substituted piperidines", J. Chem. Soc., Chem. Commun, 6, 633-640. 1998.

[5] Andrew M., Alan A. "Saturated nitrogen hetrocycles", J. Chem. Soc., Perkin Trans.1, 2862-2892. 2000.

[6] Mitchinson A., Nadin A. "Saturated nitrogen heterocycles", J. Chem. Soc., Perkin Trans. 1, 2862-2892. 2000.

[7] Laschat S., Dickner T., "Stereoselective synthesis of piperidines. Synthesis", Thieme Connect.13, 1781-1813, 2000.

[8] Fanelli, D. L.; Szewczyk, J. M.; Zhang, Y.; Reddy, G. V.; Burns, D. M.; Davis, F. A. "Sulfinimines (Thiooximine S-Oxides): Asymmetric Synthesis of Methyl (R)-(+)- $\beta$ -
Phenylalanate from $\quad(\mathrm{S})-(+)-\mathrm{N}-$

(Benzylidene)-p-Toluenesulfinamide

Benzenepropanoic acid, $\beta$-amino-, (R)-, methyl ester from Benzenesulfinamide, 4methyl-N-(phenylmethylene)- [S-(E)]", Org. Synth. 77, 50-63. 1999.

[9] Davis, F. A.; Chao, B.; Fang, T.; "Szewczyk, J. M. $\delta$-Amino $\beta$-Keto Esters, a Designed Polyfunctionalized Chiral Building Block for Alkaloid Synthesis. Asymmetric Synthesis of $(R)-(+)-2-$ Phenylpiperidine and (-)-SS20846A", Org. Lett. 2, 1041-1043. 2000.

[10] Davis F. A.; Chao, B. "Alkaloid Synthesis Using Chiral $\delta$-Amino $\beta$-Ketoesters: A Stereoselective Synthesis of (-)-Lasubine II", Org. Lett. 2, 2623-2625. 2000.

[11] Noller C., Baliah. V. J. "The Preparation of Some Piperidine Derivatives by the Mannich Reaction Am", Chem. SOC. 70. 385- 3855. 1948.

[12] Baliah V., Ekambaram, A., Govindarajan T.S. "Condensation of Acetone with Aldehydes and Ammonia Curr", Sci. 23, 264-270. 1954.

[13] Baliah, V., Govindarajan, T. S. "Synthesis of Some 4-Piperidone Derivatives Curr", Sci. 23, 91-92. 1954.

[14] Baliah, V., Ekambaram, A. J. "Studies on conformation I: Preparation and stereochemistry of some 4-piperidinols", Indian Chem. SOC. 33, 274-283. 1955.

[15] Baliah, V.; Gopalakrishnan, V. J. "Synthesis, Structural Stability Calculation, and Antibacterial Evaluation of Novel 3, 5Diphenylcyclohex-2-en-1-one Derivatives. Ind", Chem. Soc. 954, 31-50. 1954.

[16] Johnson T. A., Curtis M. D. Beak P. J. "Highly Diastereoselective and Enantioselective Carbon-Carbon Bond Formations in Conjugate Additions of Lithiated N-Boc Allylamines to Nitroalkenes: Enantioselective Synthesis of 3,4- and 3,4,5-Substituted Piperidines Including (-)-Paroxetine", J. Am. Chem. Soc.123, 1004-1005. 2001.

[17] Mannich, C. Arch. Pharm. (Weinheim, Ger) 255, 261. 1971.

[18] Mailey, E. A.; Day, A, R. "Synthesis of Derivatives of Alkylated and Arylated Piperidones and Piperidinols", J. Org. Chem. 22, 1061-1065. 1957. 
[19] Lyle, R. E.; Lyle, G. G. "Resolution of 2,6-Diphenyl-1-methyl-4-piperidone Oxime, a Novel Example of Molecular Isomerism $^{1,2,}$, J. Org. Chem.24, 1679-1684. 1959.

[20] Prostakov N. S., Vasilev, G. A., Zvolinskii, V. P., Varlamov, A. V., Savina, A. A., Sorokin, O. I., Lopatina, N. D. "Synthesis of 3-alkyl-2, 4, 6triphenylpyridines and 1,3-diphenyl-4- and2-azafluorenes”, Khim. Geterotsikl. Soedin. 11 971-975. 1975.

[21] Prostakov, N. S.; Fedorov, V. 0. \& Soldatinkov, A. T.(1979), "Production of 1azafluorene from 2-methyl-3phenylpyridine", Khim. Geterotsikl. Soedin, 15, 902-904. 1979.

[22] Franklin A., Davis B., Chao T. F., "Joanna M.S. $\delta$-Amino $\beta$-Keto Esters, a Designed Polyfunctionalized Chiral Building Block for Alkaloid Synthesis. Asymmetric Synthesis of (R)-(+)-2Phenylpiperidine and (-)-SS20846A”, J. M. Org. Lett. 2, 1041-1043. 2000.

[23] Davis F. A.; Fang T., Chao B., Burns D. "Asymmetric Synthesis of the Four Stereoisomers of 4-Hydroxypipecolic Acid", Synthesis, 14, 2106-2112. 2000.

[24] Monn J. A., Valli M. J. Johnson B. G., Salhoff C. R., Wright R. A., Howe T., Bond, A. Lodge D., Spangle L. A., Paschal J. W., Campbell J. B., Griffey K., Tizzano J. P., Schoepp, D. D. J. Med. Chem. 39, 2990-3000. 1996.

[25] Kami L.H., Melanie S. S. "Catalytic and Highly Regioselective Cross-Coupling of Aromatic C-H Substrates", J. Am. Chem. Soc., 129, 11904-11905. 2007.

[26] Kam T. S., Choo Y. M.. Komiyama K. "Unusual spirocyclic macroline alkaloids, nitrogenous derivatives, and a cytotoxic bisindole from Alstonia", Tetrahedron, 60, 3957-3966. 2004.

[27] Dietz J., Martin S. F. "Novel entry to the tricyclic core of stemofoline and didehydrostemofoline", Tetrahedron Lett, 52, 2048-2050. 2011.

[28] Smith A. B., Charnley A. K., "Hirschmann, R. Pyrrolinone-Based Peptidomimetics", Acc. Chem. Res., 44, 180-193. 2011.
[29] Kam T. S., Choo Y. M., "Komiyama K. Unusual spirocyclic macroline alkaloids, nitrogenous derivatives, and a cytotoxic bisindole from Alstonia" Tetrahedron,60, 3957-3966. 2004.

[30] Sampath N., Mathews R., Ponnuswamy M. N. "Crystal Structure and Conformation Study of 3-Methyl-2, 6-bis (4-chlorophenyl) Piperidin-4-one Thiosemicarbazone Derivative", J.Chemical Crystallography, 40, 1099-1104. 2004.

[31] Sampath N., Malathy S.M. Nethaji M., Ponnuswamy M. N. J. Chem. Crstallography 40, 1099-1104. 2010.

[32] Bruker program 1D WIN-NMR (release 6.0) and 2D WIN- NMR (release 6.1).

[33] Sampath N., Mathews R., Ponnuswamy M. N., "Crystal Structure and Conformation Study of 3-Methyl-2, 6-bis(4chlorophenyl)Piperidin-4-one

Thiosemicarbazone Derivative", 40, 10991104. 2010.

[34] Sampath N. M. S., Nethaji M., Ponnuswamy M. N. "2,4-dichlorobenzaldehyde 4-methylthiosemicarbazone". ActaCryst C96; 0346. 2003.

[35] Mohammad M. T., Srinivasa H.T., Hariprasad S, et al. "Enhanced liquid crystal properties in symmetric ethers containing the oxazepine core: synthesis and characterization of seven member heterocyclic dimmers", Tetrahedron, 72, 3948-3957, 2016.

[36] Mohammad A. T. Srinivasa H.T. Sie T. H., Hariprasad S., Yeap G. Y. "Synthesis and comparative studies of phase transition behaviour of new dimeric liquid crystals consisting of dimethyluracil and biphenyl cores”, J. Mol. Liq. 219,765-772. 2016. 